\title{
Wheatgrass juice to wheat grass powder: Encapsulation, physical and chemical characterization
}

\author{
Elif Akbas ${ }^{\mathrm{a}, \mathrm{b}, \mathrm{c}}$, Mete Kilercioglu ${ }^{\mathrm{b}}$, Ozge Nur Onder ${ }^{\mathrm{b}}$, Alperen Koker ${ }^{\mathrm{b}}$, Betul Soyler ${ }^{\mathrm{b}}$, Mecit Halil Oztop ${ }^{\mathrm{b}, *}$ \\ a Izmir Institute of Technology, Department of Food Engineering, Gulbahce, Urla 35430, Izmir, Turkey \\ ${ }^{\mathrm{b}}$ Middle East Technical University, Department of Food Engineering, Universiteler Mah., Dumlupinar Bulvari, No: 1, Cankaya 06800, Ankara, Turkey \\ ' GINOSA Food, Machine Export, and Import Industrial Limited Corporation, Universiteler Mah., Ihsan Dogramacı Bulvari, No: 13, Cankaya 06800, Ankara, Turkey
}

\section{A R T I C L E I N F O}

\section{Article history:}

Received 29 May 2016

Received in revised form 27 September 2016

Accepted 2 November 2016

Available online 23 November 2016

\section{Keywords:}

Wheatgrass

Encapsulation

Digestion

Antioxidant activity

Phenolics

\begin{abstract}
A B S T R A C T
Wheatgrass juice (Triticum aestivum L.) is known as a healthy drink due to its high antioxidant activity and phenolic content. In order to avoid the undesirable odor and protect the functional compounds, wheatgrass juice was encapsulated using maltodextrin and whey protein. Antioxidant and phenolic content, mean particle size and distribution, morphology, simulated digestion and thermal stability experiments were conducted on the encapsulated powders. Results showed that antioxidant activity was in between 0.30 and $0.06 \mathrm{mg}$ 2-diphenyl-1-picrylhydrazyl (DPPH)/g powder and phenolic content was $3.52-2.28 \mathrm{mg}$ gallic acid equivalent (GAE)/g powder. Encapsulated powders showed good stability in gastric juice and had $62 \%$ higher phenolic content compared to the intestinal fluid within 10 min digestion. Phenolic content of powders was also protected against thermal treatment at $40^{\circ} \mathrm{C}, 55^{\circ} \mathrm{C}$ and $70{ }^{\circ} \mathrm{C}$. Kinetic parameters for degradation of the phenolics were well estimated $\left(R^{2} \geqslant 0.85\right)$ using fractional conversion model.
\end{abstract}

(c) 2016 Elsevier Ltd. All rights reserved.

\section{Introduction}

Wheat (Triticum aestivum L.) has a crucial role on human diet in most countries. Many epidemiological studies have proposed that adding whole grain and whole grain products to the diet has a protective contribution against chronic diseases (Aydos, Avci, Ozkan, Karadag, \& Gurleyik, 2011). Following germination of wheat (Triticum aestivum L.) for 6-10 days, sprouts formed are called "wheatgrass". Changes during germination and sprouting lead the plants to synthesize compounds like vitamins, antioxidants or phenolics (Kulkarni, Acharya, Nair, Rajurkar, \& Reddy, 2006). The most important active component in wheatgrass is chlorophyll that is known to have an active role for the inhibition of the metabolic activation of carcinogens (Aydos et al., 2011).

Wheatgrass (Triticum aestivum $\mathrm{L}$.) is also known as a rich source of antioxidants, vitamins, including A, C and $\mathrm{E}$ and minerals such as iron, calcium, magnesium, and benzo(a)pyrene in a bioavailable form (Aydos et al., 2011; Hanninen, Rauma, Kaartinen, \&

Abbreviations: WGJ, Wheatgrass juice; GAE, gallic acid equivalent; DPPH, 2diphenyl-1-picrylhydrazyl; CCR, core to coating; W, Whey protein isolate; MD, Maltodextrin; WGP, wheatgrass powder; SEM, scanning electron microscopy.

* Corresponding author.

E-mail address: mecit@metu.edu.tr (M.H. Oztop).
Nenonen, 1999). Among the phenolic compounds found in wheatgrass, ferulic acid, gallic acid, caffeic acid, syringic acid and pcoumaric acid are the major ones. (Akcan Kardas \& Durucasu, 2014; Benincasa et al., 2015).

Antioxidants are essential compounds in food products that are very effective to prevent harmful reactions like oxidation of lipids caused by oxidative stress (Ingold, 1968). Phenolic components are secondary metabolites that are formed by plants against stress conditions during growth (Beckman, 2000). However, bioactives including antioxidants and phenolic compounds are unstable as soon as they are removed from their natural environment. Therefore, they need to be protected against undesirable interactions and reactions.

Nano and micro-encapsulation provide bioactive agents to be capsulated with secondary coating components as a tiny particle in nanometer and micrometer range to give the agents many useful properties (Augustin, Sanguansri, \& Lockett, 2013; Gharsallaoui, Roudaut, Chambin, Voilley, \& Saurel, 2007). There could be several reasons to use microencapsulation in food industry; i) decrease the core reactivity with the environmental factors, ii) lower the diffusion rate of the core components to the outside, iii) promote easier handling, iv) control the release of the core component, v) prevent undesirable taste of the core component and vi) dilute the core component due to requirement of small amounts (Shahidi \& Han, 
1993). Types of the microcapsules can be simple spheres, irregular shapes, multi-core materials, multi-wall components or several core materials in a coating matrix, depending on the physicochemical properties, the wall composition and microencapsulation techniques (Dziezak, 1988; Gharsallaoui et al., 2007).

Encapsulation of active agents for foods could be achieved by using different techniques. In order to preserve the heat sensitive food compounds for long-term storage, freeze drying, also known as lyophilization, is a convenient method. Freeze drying is based on sublimation and provides food materials to conserve its properties like shape, appearance, color, taste, texture (Nedovic, Kalusevic, Manojlovic, Levic, \& Bugarski, 2011; Ray, Raychaudhuri, \& Chakraborty, 2015).

Studies have proposed that use of carrier agents like maltodextrin could protect sensitive compounds like ascorbic acid in fruit juice (Murali, Kar, Mohapatra, \& Kalia, 2014). Whey protein isolate also is used in various encapsulated formulations due to its film forming and stretching abilities (Rajam, Karthik, Parthasarathi, Joseph, \& Anandharamakrishnan, 2012).

The aim of this study was to encapsulate wheatgrass juice (WGJ) in powder form and to characterize these capsules in terms of particle size, morphology, digestibility behavior at simulated gastric and intestinal fluids and assess the kinetic stability at different temperatures.

\section{Materials and methods}

\subsection{Chemicals}

Wheatgrass juice (WGJ) was obtained from Freshot Inc. (Ankara, Turkey). Ethanol, methanol, $\mathrm{NaOH}, \mathrm{HCl}$, acetic acid, gallic acid, sodium carbonate, Folin-Ciocalteau reagent, 2-diphenyl-1picrylhydrazyl (DPPH), potassium phosphate, monobasic potassium phosphate, pepsin from porcine gastric mucosa and pancreatin from porcine pancreas were purchased from Sigma (St Louis, MO, USA). Maltodextrin (Dextrose equivalent:4-7) was obtained from Avebe Food (Veendam, The Netherlands) and whey protein isolate (BiPro) with a protein content of $88 \%$ was purchased from Hardline Nutrition (Istanbul, Turkey).

\subsection{Moisture content measurements}

Moisture contents of the encapsulated WGJ were determined by using an infrared moisture analyzer (Radwag Mac 50, Radom, Poland). Measurements were done after freeze drying.

\subsection{LC-MS/MS analysis}

To determine and quantify the phenolic compounds in freeze dried WGJ, LC/MS/MS experiments were conducted using the system at METU Food Engineering Food Analysis Laboratory (Applied Biosystems, MDS SCIEX 3200 Q TRAP, MA, USA). The LC-tandem MS system consisted of a Spark chromatograph coupled to a 3200 QTrap mass spectrometer equipped with a TurboVion spray (ESI) interface. Separation of phenolic acids was performed using a Synergi 4u Fusionc18 RP column (Phenomenex, $150 \mathrm{~mm}$, $2 \mathrm{~mm}, 3 \mu \mathrm{m}$ of particle size). The flow rate was set to $0.2 \mathrm{~mL} / \mathrm{min}$ and the oven temperature was kept at $24{ }^{\circ} \mathrm{C}$. Mobile phase A and phase $\mathrm{B}$ were water and acetonitrile that were acidified with $1 \%$ formic respectively.

The operation conditions for the analysis in the negative mode were as followings: Ion spray voltage $5500 \mathrm{~V}$, curtain gas $10, \mathrm{GS} 1$ and GS2, 40 and 50 psi, respectively and probe temperature was (TurboV) $500^{\circ} \mathrm{C}$. Nitrogen served as the collision gas. The optimization of MS parameters as de-clustering potential (DP), collision energy (CE) and collision cell entrance potential (CEP) were performed by flow injection analysis for each compound; entrance potential (EP) and collision cell exit potential (CXP) were set to 8 and $4 \mathrm{~V}$, respectively, for all phenolic acids.

Extraction was carried out following the procedure of Takahashi, Okiura, Saito, and Kohno (2014) and SanchezRabaneda et al. (2003) with some slight modifications. $5 \mathrm{~g}$ of freeze dried wheatgrass was added to $30 \mathrm{~mL}$ methanol and sonicated in an ultrasonic bath (Elmasonic P, Elma, Singen, Germany) for $1 \mathrm{~h}$. Following sonication, the solution was centrifuged at $15,000 \mathrm{~g}$ for $10 \mathrm{~min}$ and supernatant was removed. The residue was mixed with $15 \mathrm{~mL}$ methanol and the same procedure was repeated. The supernatant was removed and blended with the previous one. Extracts were also centrifuged and the supernatant was removed. The extract was completed to a final volume of $50 \mathrm{~mL}$ with methanol and filtered respectively through cellulose-acetate 0.45 and $0.22 \mu \mathrm{m}$ filters.

\subsection{Encapsulation}

\subsubsection{Preparation of microcapsule solutions}

Maltodextrin (MD) and whey protein isolate (W) were used as the coating materials. MD and $\mathrm{W}$ were mixed at $1: 2,2: 1,1: 3$ and $3: 1$ ratio and was stirred at $150 \mathrm{rpm}$ for 1 day. Active agent (WGJ) was added to the mixture at $1: 10,1: 20$ or $1: 40$ core to coating (CCR) ratios and pre-homogenized at $8000 \mathrm{rpm}$ for $5 \mathrm{~min}$ (IKA, UltraTurrax, Junke \& Kunkel, IKA-Labortechnik, Taufen, Germany) and then, further homogenized (Silent Crusher S, Heidolph Co. Ltd., Schwabach, Germany) at 75,000 rpm for $6 \mathrm{~min}$.

\subsubsection{Lyophilization}

Homogenized samples containing WGJ were dried for $48 \mathrm{~h}$ in a freeze dryer (LGJ-10, Beijing Songyuan, Humxing Tech. Co. Ltd., Beijing, China). Following lyophilization WGJ was transformed into a powder form that consisted of the microcapsules. These capsules will be referred as wheatgrass powder (WGP) throughout the text.

\subsection{Phenolic content determination}

\subsubsection{Determination of total phenolic content}

Folin-Ciocalteu method with slight modifications was used to determine the total phenolic content (Krawitzky et al., 2014). Initially, a calibration curve for gallic acid was prepared at a concentration range of $15-60 \mathrm{ppm}$. $1 \mathrm{~mL} 2 \mathrm{~N}$ Folin reagent was diluted with $9 \mathrm{~mL}$ distilled water. At the same time, 3.75 grams of sodium carbonate was mixed with $50 \mathrm{~mL}$ distilled water. $400 \mathrm{mg}$ WGP was dissolved in $4 \mathrm{~mL}$ ethanol, acetic acid and distilled water mixture $(50: 8: 42, v / v)$ and the resulting mixture was centrifuged at $9056 \mathrm{~g}$ for 2 min (Wisd Wise spin, Witeg Labortechnik, Wertheim, Germany). Following centrifugation $2.5 \mathrm{~mL}$ Folin solution was mixed with the $500 \mu \mathrm{L}$ supernatant and kept in dark for $5 \mathrm{~min}$. $2 \mathrm{~mL}$ sodium carbonate solution was mixed with the Folinsupernatant solution and kept in dark for $60 \mathrm{~min}$. Finally, the absorbance of the sample at $760 \mathrm{~nm}$ was measured using a UV/ VIS Spectrophotometer (Mecasys Co. LTD, Optizen Pop Nano Bio, Daejeon, Korea) in terms of gallic acid equivalents (GAE) in $\mathrm{mg}$ GAE/g powder.

\subsubsection{Determination of surface phenolic content}

For surface phenolics content the same procedure of total phenolics was followed except that wheatgrass powders were mixed with ethanol and methanol $(1: 10)$ to dissolve only the wall material. Surface phenolics was determined to measure the amount of phenolics present on the outer wall material which remained unencapsulated. 


\subsubsection{Encapsulation efficiency}

Encapsulation efficiency was defined as the ratio of encapsulated phenolic content to total phenolic content. Encapsulated phenolic content was calculated as the difference between total phenolic content and surface phenolic content. Encapsulation efficiency of the capsules was calculated using Eq. (1), where EE denoted encapsulation efficiency, TPC, SPC and EPC were total, surface and encapsulated phenolic contents respectively.

$\mathrm{EE}(\%)=\mathrm{EPC} / \mathrm{TPC} * 100=(\mathrm{TPC}-\mathrm{SPC}) / \mathrm{TPC} * 100$

\subsection{Antioxidant activity}

DPPH Radical Scavenging Method was used to determine total antioxidant activity (Wang, Li, Zeng, \& Liu, 2008). Calibration curve was prepared at a concentration range of 5-30 ppm DPPH. WGPs were mixed with ethanol, acetic acid and distilled water (50:8:42, v/v) and the mixture was centrifuged at $9056 \mathrm{~g}$ for $2 \mathrm{~min}$. DPPH $(0.0025 \mathrm{~g})$ was mixed with $100 \mathrm{~mL}$ methanol and $3.9 \mathrm{~mL}$ of that solution was added to $100 \mu \mathrm{L}$ sample solution and kept in dark for an hour. The absorbance at $517 \mathrm{~nm}$ was measured using a UV/VIS Spectrophotometer (A2). Absorbance of methanol and DPPH mixture that did not include the sample was measured as the blank (A1). Using the calibration curve absorbance values (A1, A2) were converted to concentrations C1 and C2. Antioxidant activity was calculated using Eq. (2):

$\mathrm{AA}(\mathrm{mg} \mathrm{DPPH} / \mathrm{g}$ powder $)=\frac{\left(\mathrm{C}_{1}-\mathrm{C}_{2}\right) * \mathrm{~d} * \text { Vtotal }}{\mathrm{m}}$

$\mathrm{m}$ is the weight of WGP in $\mathrm{g}$. $\mathrm{V}_{\text {total }}$ is the volume of a mixture of WGP and ethanol: acetic acid:water mixture in $\mathrm{mL}$ and $\mathrm{d}$ is dilution rate.

2.7. In vitro digestion of microcapsules in simulated gastric (SGF) and intestinal fluids (SIF)

\subsubsection{Digestion in the simulated gastric fluid (SGF)}

To prepare SGF, $2 \mathrm{~g} \mathrm{NaCl}$ and $3.2 \mathrm{~g}$ pepsin were mixed with $7 \mathrm{~mL}$ $2 \mathrm{~N} \mathrm{HCl}$ and $\mathrm{pH}$ was adjusted to 1.2 using distilled water. WGP $(0.1 \mathrm{mg})$ was added to $1.4 \mathrm{~mL}$ of SGF and that mixture was kept in a shaking water bath (WB-6, Wisd Co. Ltd., Texas, USA) for $2 \mathrm{~h}$ at $37^{\circ} \mathrm{C}$. After the sample cooled down to room temperature, it was filtered through cellulose-acetate filters $(0.45$ and $0.22 \mu \mathrm{m})$ and $0.2 \mathrm{M} \mathrm{NaOH}$ was added until the solution was neutralized. Total phenolic content of 1:20 CCR 1:2 W:MD, 1:10 CCR 3:1 W: MD and 1:10 CCR 1:2 W:MD samples were determined.

\subsubsection{Digestion in the intestinal fluid (SIF)}

$6.8 \mathrm{~g}$ monobasic potassium phosphate was mixed with $250 \mathrm{~mL}$ water while $77 \mathrm{~mL}$ of $0.2 \mathrm{M} \mathrm{NaOH}$ was dissolved in $500 \mathrm{~mL}$ distilled water. Pancreatin ( $10 \mathrm{~g}$ ) was added to the solution and filled with distilled water up to one liter. $0.2 \mathrm{M} \mathrm{NaOH}$ or $0.2 \mathrm{M} \mathrm{HCl}$ was used to adjust the $\mathrm{pH}$ to 6.8 . Final solution $(2.4 \mathrm{~mL})$ was mixed with $0.1 \mathrm{~g}$ sample and held in a water bath (WB-6, Wisd Co. Ltd., Texas, USA) for $2 \mathrm{~h}$ at $36.6^{\circ} \mathrm{C}$. After cooled down to room temperature, sample was filtered through cellulose-acetate filters. $100 \mu \mathrm{L}$ of $3 \mathrm{M} \mathrm{HCl}$ was used to decrease the $\mathrm{pH}$. Then, $0.2 \mathrm{M} \mathrm{NaOH}$ was added to the mixture to adjust the $\mathrm{pH}$ to 7 . Total phenolic content was determined for $1: 20$ CCR 1:2 W:MD, 1:10 CCR 3:1 W:MD, 1:10 CCR 1:2 W:MD samples.

\subsection{Particle size measurements}

Mean particle sizes and particle size distribution of the capsules were obtained using Mastersizer 3000 (Mastersizer 3000, Malvern Co. Ltd., Worcestershire, England. $\mathrm{D}_{[3,2]}$, the surface mean diameter was determined using Eq. (3) where $n_{i}$ and $d_{i}$ denote the number and diameter of particles respectively.

$D_{[3,2]}=\sum n_{i} d_{i}^{3} / \sum n_{i} d_{i}^{2}$

Meanwhile, span of the distribution was calculated according to Eq. (4) where $d(v, 90), d(v, 50)$ and $d(v, 10)$ are the diameters at 90 , 50 and $10 \%$ of cumulative volume, respectively.

Span $=\frac{[\mathrm{d}(\mathrm{v}, 90)-\mathrm{d}(\mathrm{v}, 10)]}{\mathrm{d}(\mathrm{v}, 50)}$

\subsection{Surface morphology analysis}

Capsules' morphology was analyzed using scanning electron microscopy (SEM). JSM-6400 Electron Microscope (JEOL Ltd, Tokyo, Japan) equipped with NORAN System 6 X-ray Microanalysis System and Semafore Digitizer was used to monitor the outer surface of the capsules at $20 \mathrm{kV}$ by coating samples with gold/palladium under vacuum. SEM images were obtained at magnifications of $100-25,000 \times$ for 3 different samples.

\subsection{Kinetic study for the microcapsules}

To evaluate the heat stability of the capsules formulated, total phenolic contents of the capsules were determined at 3 different temperatures $\left(40^{\circ} \mathrm{C}{ }^{\circ} \mathrm{C}, 55^{\circ} \mathrm{C}, 70^{\circ} \mathrm{C}\right)$ for $1 \mathrm{~h}$ between $12 \mathrm{~min}$ intervals. The degradation rate constants of WGPs during thermal treatment were calculated using the first order kinetics with fractional conversion model as given in (Knockaert et al., 2012) Eq. (5).

$\mathrm{C}=\mathrm{C}_{\mathrm{f}}+\left(\mathrm{C}_{0}-\mathrm{C}_{\mathrm{f}}\right) \exp (-\mathrm{kt})$

$\mathrm{C}$ denoted the phenolic content of WGP at time $t, \mathrm{C}_{\mathrm{f}}$ the phenolic content of WGP at equilibrium state, and $C_{0}$ the initial phenolic content of WGP, $\mathrm{k}$ the reaction rate constant $\left(\mathrm{min}^{-1}\right)$ and $\mathrm{t}$ the treatment time (min).

Activation energy was found using Arrhenius equation as given in Eq. (6) where $\mathrm{k}$ represented the reaction rate constant $\left(\mathrm{min}^{-1}\right)$, $E_{a}$ the activation energy $(\mathrm{J} / \mathrm{mol}), \quad R$ the ideal gas constant $(8.314 \mathrm{~J} / \mathrm{mol} . \mathrm{K})$ and $\mathrm{T}$ the temperature $(\mathrm{K})$.

$\ln (\mathrm{k})=-\frac{\mathrm{E}_{\mathrm{a}}}{\mathrm{R}}\left(\frac{1}{\mathrm{~T}}\right)+\ln (\mathrm{A})$

\subsection{Statistical analysis}

Results reported represented the mean of at least three replicates with standard errors. ANOVA was conducted to determine the differences between samples and for the significance differences found, Tukey test was performed as the multiple comparison test using Minitab V16 (Minitab Co. Ltd., Coventry, UK)

\section{Results and discussion}

\subsection{Moisture contents}

Moisture content is one of the most important attributes which could affect the shelf life of food products, particularly the dried ones. Following freeze drying, encapsulated wheatgrass powders (WGP) were immediately sealed to prevent moisture uptake. Moisture contents of the samples were measured between $4.2 \%$ and $8.7 \%$ as seen in Fig. 1. Practically, for food industry the moisture content of dried powders is expected to be between $3 \%$ and $10 \%$ (Li et al., 2015). These results indicated that moisture contents of WGPs were under specified range. 


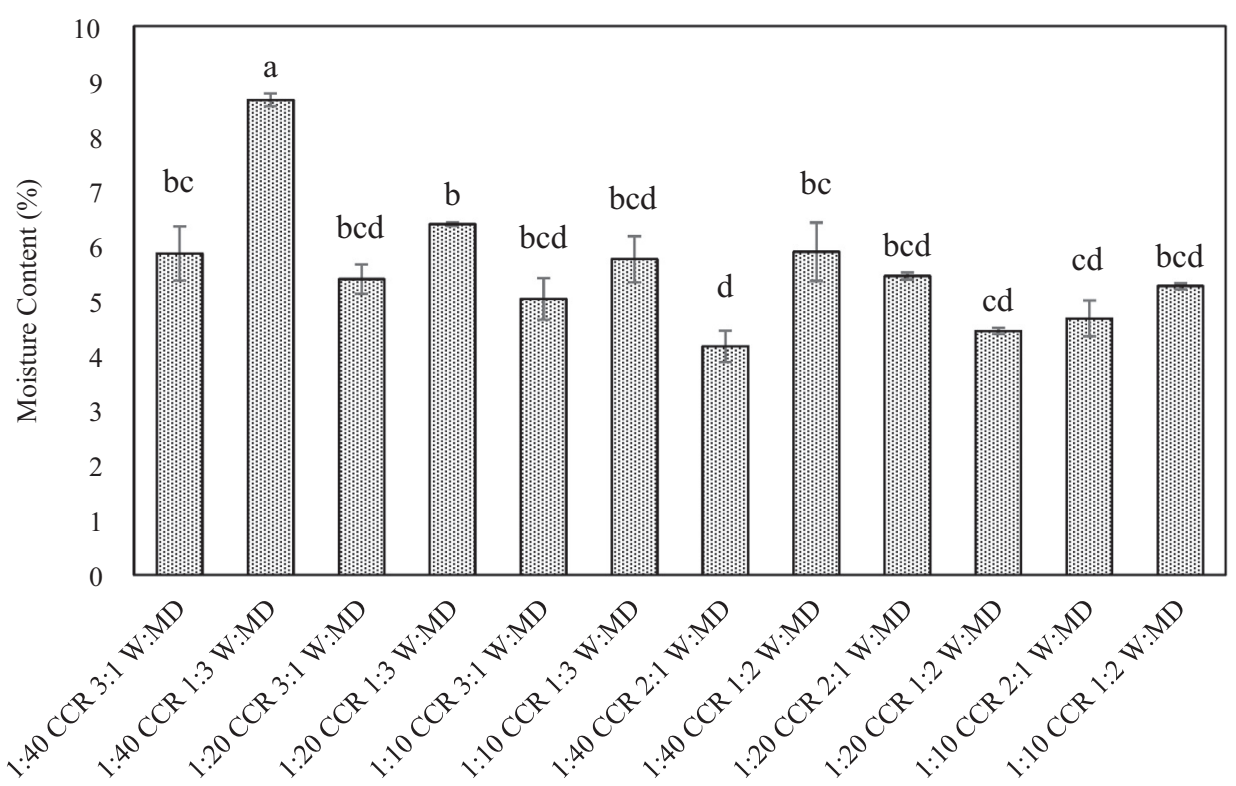

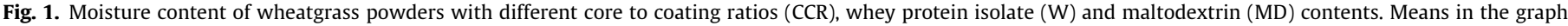
indicated by different letters are significantly different $(p \leqslant 0.05)$.

\subsection{Particle sizes and size distributions}

Mean particle sizes and span values of the samples are given in Fig. 2. Span values showed that encapsulated powders included particles within a wide range of diameters. The span values of WGPs were fairly in a small range (1.62-3.49) and mean particle sizes changed between 23.5 and $9.73 \mu \mathrm{m}$. It can be seen in Fig. 2 that freeze dried WGJ had the largest particle size and span value. On the other hand, the samples prepared with wall materials had significantly lower particle sizes and span values due to homogenization in high-speed blender and silent crusher. Possible reason for the observed decreased in particle size was that these homogenizers created shear force that caused new droplets formation with relatively small sizes and then wall materials, which facilitated the small droplet formation, covering them to inhibit droplet aggregation (Bae \& Lee, 2008; Maali \& Mosavian, 2013). On the other hand, particle size results indicated that increasing core material content created larger particles which had higher span values. The reason was that wall material was not able to cover the large particles of wheatgrass juice so larger particles remained uncoated. For all CCR ratios, there was a significant decrease in particle sizes when whey protein content increased $(P<0.05)$. This

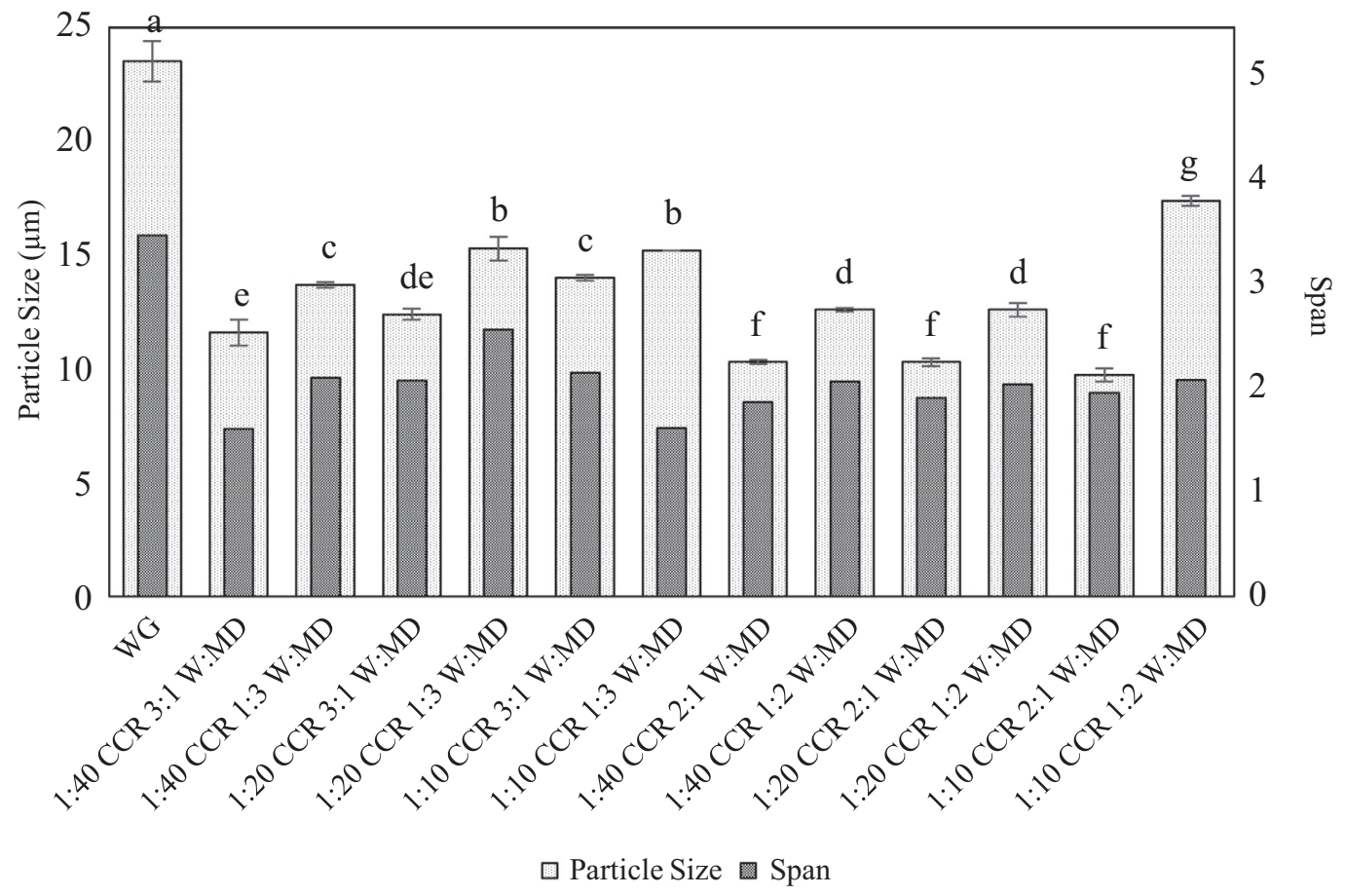

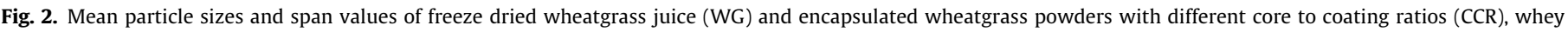
protein isolate $(\mathrm{W})$ and maltodextrin (MD) contents. Means in the graph indicated by different letters are significantly different $(\mathrm{p} \leqslant 0.05)$. 
was explained by the good adsorption ability of whey protein on the core-wall material interfaces and formation of lower size droplets. A previous work was also consistent with the results which showed that use of whey protein as the wall material resulted in smaller droplet size (Jafari, Assadpoor, He, \& Bhandari, 2008).

\subsection{Surface morphology analysis}

The morphologies of WGPs were observed by scanning electron microscopy (SEM). SEM images are given in Fig. 3. Samples having W:MD ratio of 1:2 showed almost smooth, similar surfaces with each other at all CCR ratios. SEM images also revealed that there were lots of surface cracks and also sharp edged, irregular shaped particles. This was explained by the insufficient surface coating materials and these cracks could be the ones present on nonencapsulated freeze dried WGJ as seen in Fig. 3-J, K, L. On the other hand, with increase in whey protein content, the surface became more porous and a sort of collapse from surface of WGP was observed (Fig. 3-G, H, I). In another study, it was shown that in carbohydrate/protein mixture system through rapid freezing, carbohydrates crystallized rather than becoming glass. The crystal growth and applied mechanical forces on the protein resulted in aggregation and collapse (Millqvist-fureby \& Malmsten, 1999). In protein rich systems, these effects might be observed excessively.
The structural collapse that was more apparent in samples of 3:1 W:MD ratio could be attributed to these effects.

\subsection{Antioxidant activities}

The antioxidant activities of WGPs are given in Fig. 4. Samples having CCR ratio of $1: 10$ and $W: M D$ ratio of $1: 2$ were shown to have the highest antioxidant activity $(0.30 \mathrm{mg} \mathrm{DPPH} / \mathrm{g}$ powder $)$. Samples having CCR ratio of $1: 40$ and W:MD ratio of $3: 1$ were shown to have the lowest antioxidant activity $(0.06 \mathrm{mg} \mathrm{DPPH} / \mathrm{g}$ powder). As shown in Table 1, freeze dried WGP contained various compounds which possessed antioxidant activity and an increase in the WPJ concentration increased the antioxidant activity for all $\mathrm{W}$ :MD ratios. On the other hand, the changes in the ratios of coating materials didn't affect the antioxidant activity of WGP significantly $(P>0.05)$. Several studies showed that antioxidant activity of wheatgrass was affected with different planting conditions, harvesting period or wheat species, but in common all studies suggested that wheatgrass had high antioxidant activity due to different phenolic compounds and flavonoids present in the samples (Aydos et al., 2011; Durairaj, Shakya, Pajaniradje, \& Rajagopalan, 2014; Kulkarni et al., 2006; Shukla, Vashistha, \& Singh, 2009; Sun, Li, \& Chen, 2014; Zendehbad, Mehran, \& Malla, 2014).

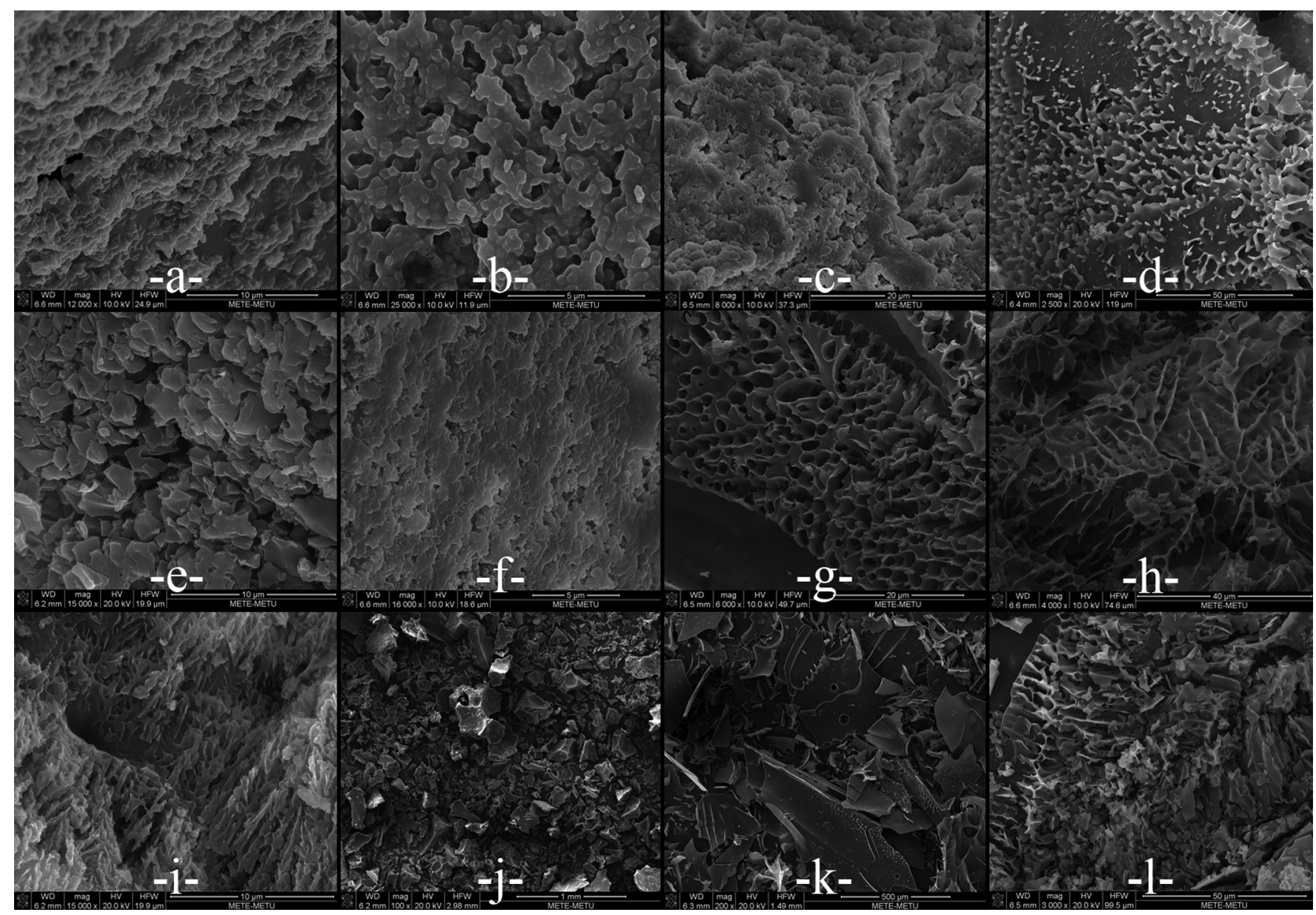

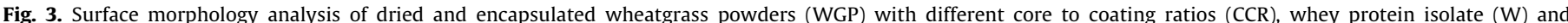

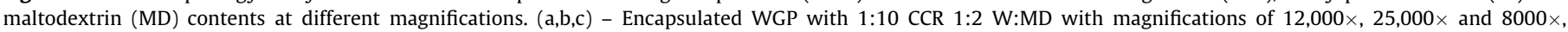

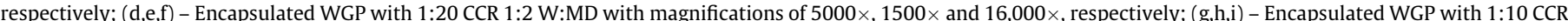

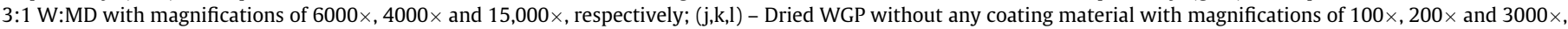
respectively. 


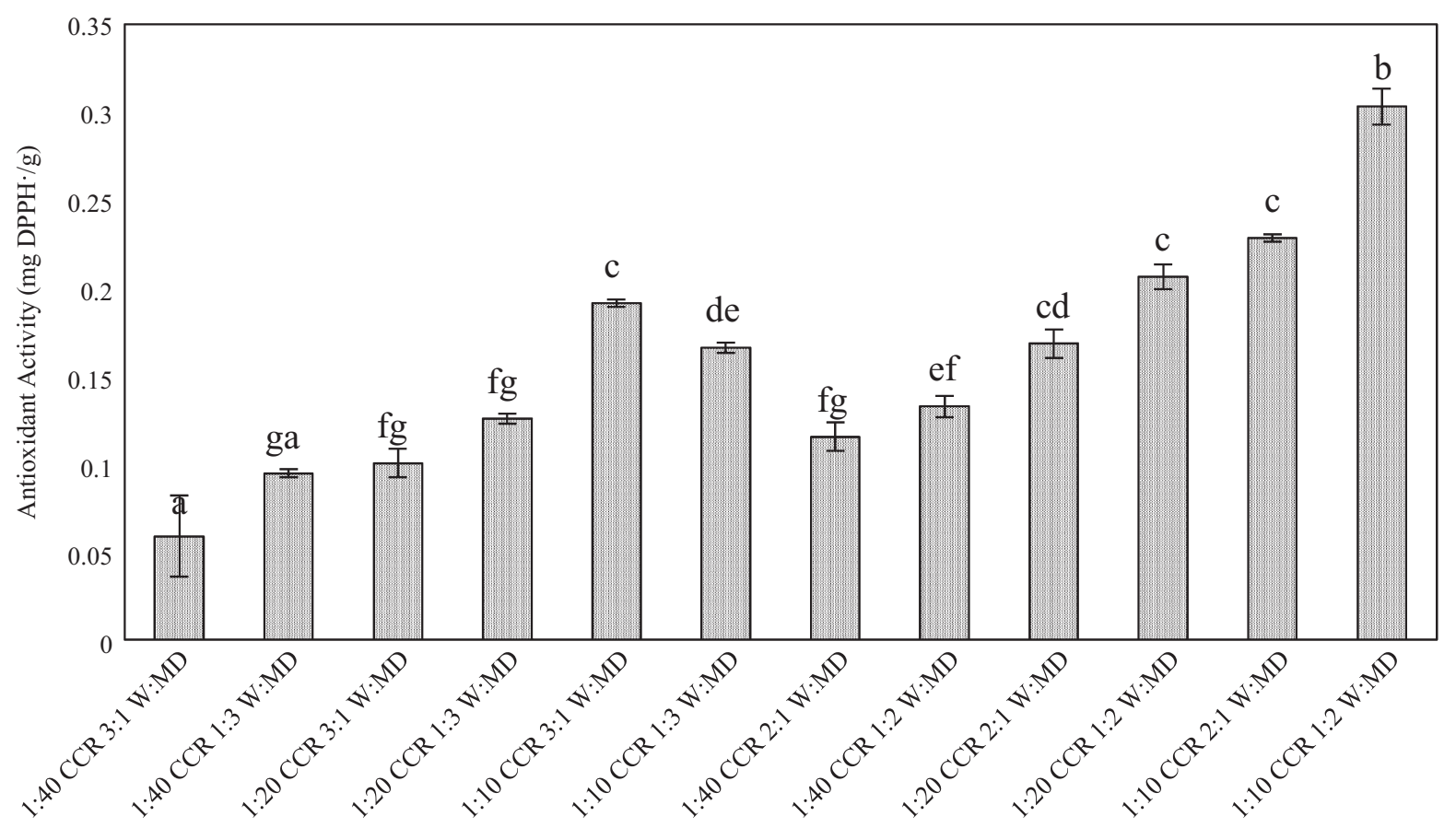

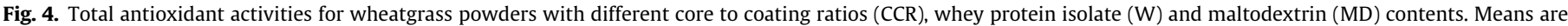
represented as mg DPPH (2-diphenyl-1-picrylhydrazyl)/g powder. Means in the graph indicated by different letters are significantly different ( $\mathrm{p} \leqslant 0.05)$.

Table 1

Antioxidant activity (mg DPPH- 2-diphenyl-1-picrylhydrazyl/g powder), total phenolic content (mg GAE-gallic acid equivalent/g powder) and phenolic acid profile according to LC/MS/MS analysis of freeze dried wheatgrass juice (WG). Data are reported as the mean \pm standard error. (ND: Not detected).

\begin{tabular}{ll}
\hline & Freeze Dried WG \\
\hline Total antioxidant activity (mg DPPH/g powder) & $0.67 \pm 0.023$ \\
Total phenolic content $(\mathrm{mg}$ GAE/g powder) & $6.73 \pm 0.23$ \\
Caffeic acid $(\mu \mathrm{g} / \mathrm{g}$ powder) & $11.5 \pm 0.57$ \\
Gallic acid $(\mu \mathrm{g} / \mathrm{g}$ powder$)$ & $2.74 \pm 0.26$ \\
p-Coumaric acid $(\mu \mathrm{g} / \mathrm{g}$ powder $)$ & $\mathrm{ND}$ \\
Chlorogenic acid $(\mu \mathrm{g} / \mathrm{g}$ powder$)$ & $270 \pm 15.21$ \\
Ferulic acid $(\mu \mathrm{g} / \mathrm{g}$ powder) & $1020 \pm 275.55$ \\
Quercetin $(\mu \mathrm{g} / \mathrm{g}$ powder $)$ & $\mathrm{ND}$ \\
\hline
\end{tabular}

\subsection{Total phenolic contents}

The phenolic acid profile of WGJ, which used in this study, was analyzed with LC/MS/MS and data are shown in Table 1. Ferulic acid was the primary phenolic acid composed of $78 \%$ of the total phenolic compounds. In literature, the phenolic acids present in wheatgrass were ferulic acid being the major one followed by vanillic acid, gallic acid, caffeic acid, syringic acid and p-coumaric acid (Adom \& Liu, 2002; Akcan Kardas \& Durucasu, 2014). Our results were consistent with previous findings that ferulic acid was the major compound found in wheatgrass. The difference between the phenolic acid profile of the literature and our findings could be due to the genotype of the wheat, harvesting conditions and environmental factors (Beta, Sapirstein, \& Mpofu, 2006).

Results of the total phenolic content of WGPs according to Folin-Ciocalteu method are given in Fig. 5. The capsules having CCR ratio of $1: 10$ and $W: M D$ ratio of $3: 1$ had the highest and the capsules in CCR ratio of 1:40 and W:MD ratio of $1: 2$ had the lowest phenolic contents of 3.63 and $2.28 \mathrm{mg} \mathrm{GAE} / \mathrm{g}$ powder respectively. Results showed that $C C R$ ratio and the $\mathrm{W}$ :MD proportion had a significant effect on total phenolic contents $(\mathrm{P}<0.05)$. A similar result was also observed in antioxidant activity experiments.

\subsection{Encapsulation efficiency}

It is important to reduce the surface phenolic acid quantity to ensure long-term stability of WGP. The encapsulation efficiency was calculated as the ratio of the difference between the total and surface phenolic content to total phenolic content of the WGP. Wall and core material property, encapsulation process type or conditions have a great impact on encapsulation efficiency (Gharsallaoui et al., 2007; Goula \& Adamopoulos, 2012; Jafari et al., 2008; Reineccius, 2004). The encapsulation efficiency results were shown in Fig. 5 and efficiencies varied from $53 \%$ for the samples of the CCR ratio 1:40 and W:MD ratio of $2: 1-77 \%$ with the CCR ratio of $1: 10$ and $W: M D$ ratio of $1: 2$. The study represented by Robert et al. (2010) reported that maltodextrin showed greater barrier properties on the phenolics and anthocyanins of pomegranate juice. A similar case was observed in this study that coatings which included maltodextrin showed better efficiency than whey protein as a coating. Even though an increase in CCR ratio seemed to give higher stability, there must be a balance between the core and coating material to improve encapsulation efficiency. Young, Sarda, and Rosenberg (1993) showed that the encapsulation efficiency of anhydrous milk fat decreased as the ratio of whey protein isolate: carbohydrate increased. In the present study, a similar result was observed that as the proportion of wall material $(\mathrm{W}$ : MD), increased, encapsulation efficiency decreased. Also, Drusch, Serfert, Van Den Heuvel, and Schwarz (2006) showed that agglomeration or collapses of encapsulated particles changed the structural boundaries and morphologies that caused core material being thrown out of the wall matrix due to compression. This could be the reason why increasing the CCR ratio decreased encapsulation efficiency. In addition, results showed that encapsulation efficiency was positively correlated with particle size (Pearson's correlation coefficient $\mathrm{R}=0.605, \mathrm{P}<0.05$ ). The relations between the particle size and encapsulation efficiency is not clear but, Soottitantawat et al. (2005) hypothesized that larger particles contributed to retain core material and stability. Also, in a study by Finney, Buffo, and Reineccius (2002), it was observed that as sur- 


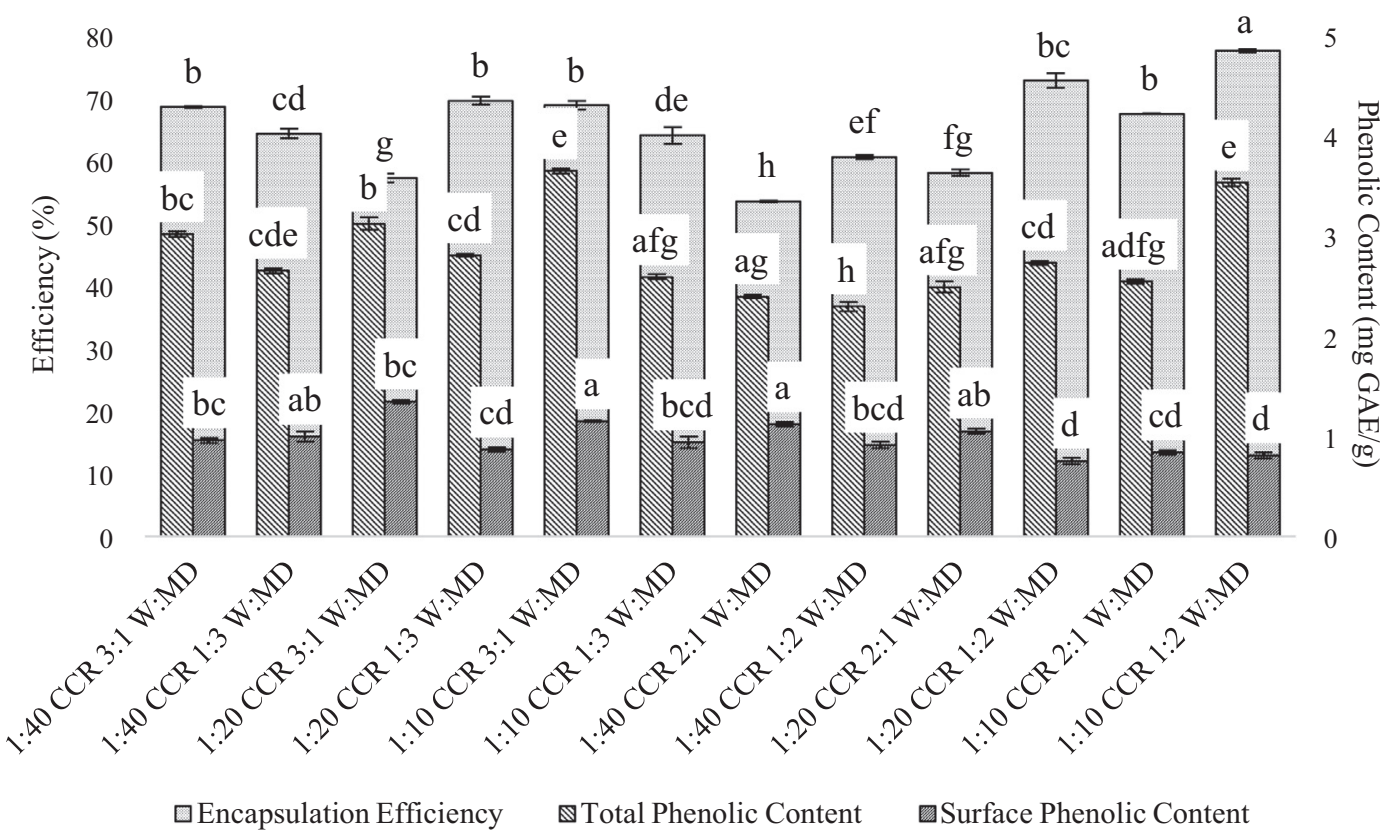

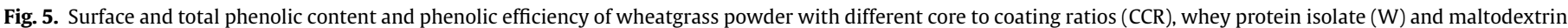

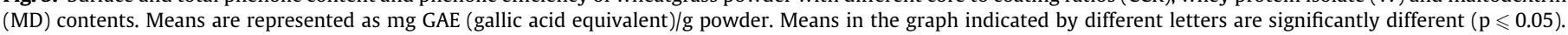

face areas of large particles decreased better retention of the core material was achieved.

\subsection{Digestibility of WGE}

Protection of phenolics from the harsh gastric conditions is an important issue that is limiting the bioavailability of phenolic compounds (Anal \& Singh, 2007; Vandenberg, Drolet, Scott, \& De la Noüe, 2001). Gastric juice penetrates to the food and helps digestion via enzyme and/or acidity but the exact action of these have not been clearly explained yet (Kong \& Singh, 2009). Obtaining active molecular compounds and transferring these to the target units within the organism requires a carrier system design (Chen, Remondetto, \& Subirade, 2006). In addition, due to alkali nature of the intestinal fluid, some active compounds may become soluble (Sansone et al., 2011). In that regard, encapsulation could provide protection on gastrointestinal media and provide longer release times. In order to identify the behavior of the wheatgrass powders in gastrointestinal environment, in vitro experiments were performed under simulated gastric and intestinal juices for $10 \mathrm{~min}$ and $120 \mathrm{~min}(2 \mathrm{~h})$. Digestion was evaluated based on the total phenolic content of different samples exposed to gastric and intestinal juices for different times. As shown in Fig. 6 the digestion affected freeze dried WGJ more compared to encapsulated form in W:MD. At the same W:MD proportion (1:2), the TPC of the different CCR showed significantly different results $(P<0.05)$. It was $1.83 \mathrm{mg}$ GAE/g powder for CCR of $1: 20$ and $1.47 \mathrm{mg}$ GAE/g powder for $1: 10$ in gastric juice within two hours whereas $1.69 \mathrm{mg} \mathrm{GAE} / \mathrm{g}$ powder for CCR of $1: 20$ and $1.66 \mathrm{mg} \mathrm{GAE} / \mathrm{g}$ powder for $1: 10$ within $10 \mathrm{~min}$.

The amount of phenolics on encapsulated powder surface was higher for $1: 20$ CCR ratio than the $1: 10$ as $72 \%$ and $77 \%$ respectively. WGJ was well preserved when the CCR ratio was $1: 10$. In this study, it was observed that those phenolics of WGPs released at a slower rate in gastric juice compared to intestinal juice. This was associated with the hydrolysis of $\mathrm{W}$ :MD capsules at this $\mathrm{pH}$. A similar work was carried out by Zheng, Ding, Zhang, and Sun (2011) where bayberry polyphenols were encapsulated with ethyl cellulose and release rates were found to be higher in the intestinal fluid than gastric fluid. In addition, the change in W:MD proportion from 3:1 to $1: 2$ increased the total phenolic content in gastric juice $(\mathrm{P}<0.05)$ and decreased in intestinal juices. It is probably due to $\beta-$ lactoglobulin present in whey protein isolate. The globular structure could have prevented the digestion of $\beta$-lactoglobulin toward the enzyme pepsin (Fu, Abbott, \& Hatzos, 2002; Schmidt, Meijer, Slangen, \& Van Beresteijn, 2006; Wang \& Zhong, 2014). However, almost complete digestion of $\beta$-lactoglobulin was observed in the intestinal environment under the influence of pancreatin (Fu et al., 2002; Schmidt et al., 2006). Sarkar, Horne, and Singh (2010) reported that intestinal fluid composed of pancreatin as well as bile salts which changed the lipase action through binding the protein-coated droplets and resulted in the breakdown of the capsule. Overall, $34 \%$ and $29 \%$ higher phenolic content were measured in gastric juice than intestinal juice within $10 \mathrm{~min}$ and $2 \mathrm{~h}$ respectively for encapsulated powder of 1:20 CCR ratio. In powders with 1:10 CCR ratio, similar gastric-intestinal juice relations were observed and within $10 \mathrm{~min}, 62 \%$ and 50\% higher phenolic content

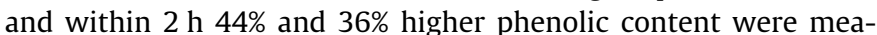
sured in powders with W:MD ratio 3:1 and 1:2 respectively. The study revealed that WGPs were well dissolved in intestinal media.

\subsection{Temperature stability of the capsules}

The stability of selected WGPs at different temperatures and times were examined. The phenolic content of WGPs dramatically decreased at the initial $12 \mathrm{~min}$. After $12 \mathrm{~min}$, the degradation was almost stabilized. As expected, higher loss of phenolics (36\%) was recorded at the end of $60 \mathrm{~min}$ at $70{ }^{\circ} \mathrm{C}$. At low temperatures as 40 and $55{ }^{\circ} \mathrm{C}$, more than $70 \%$ of the phenolic contents were kept and no significant differences were observed between the samples $(P>0.05)$. The wall materials were found to be successful in ensuring stability during heating. In Table 2 , reaction rate constants and activation energies of WGPs are given. Fractional conversion model well fit the kinetic data obtained from WGPs at different temperatures $\left(R^{2}>0.85\right)$. Moreover, for each temperature the highest rate constant was calculated for the sample of the CCR ratio 1:10 and 


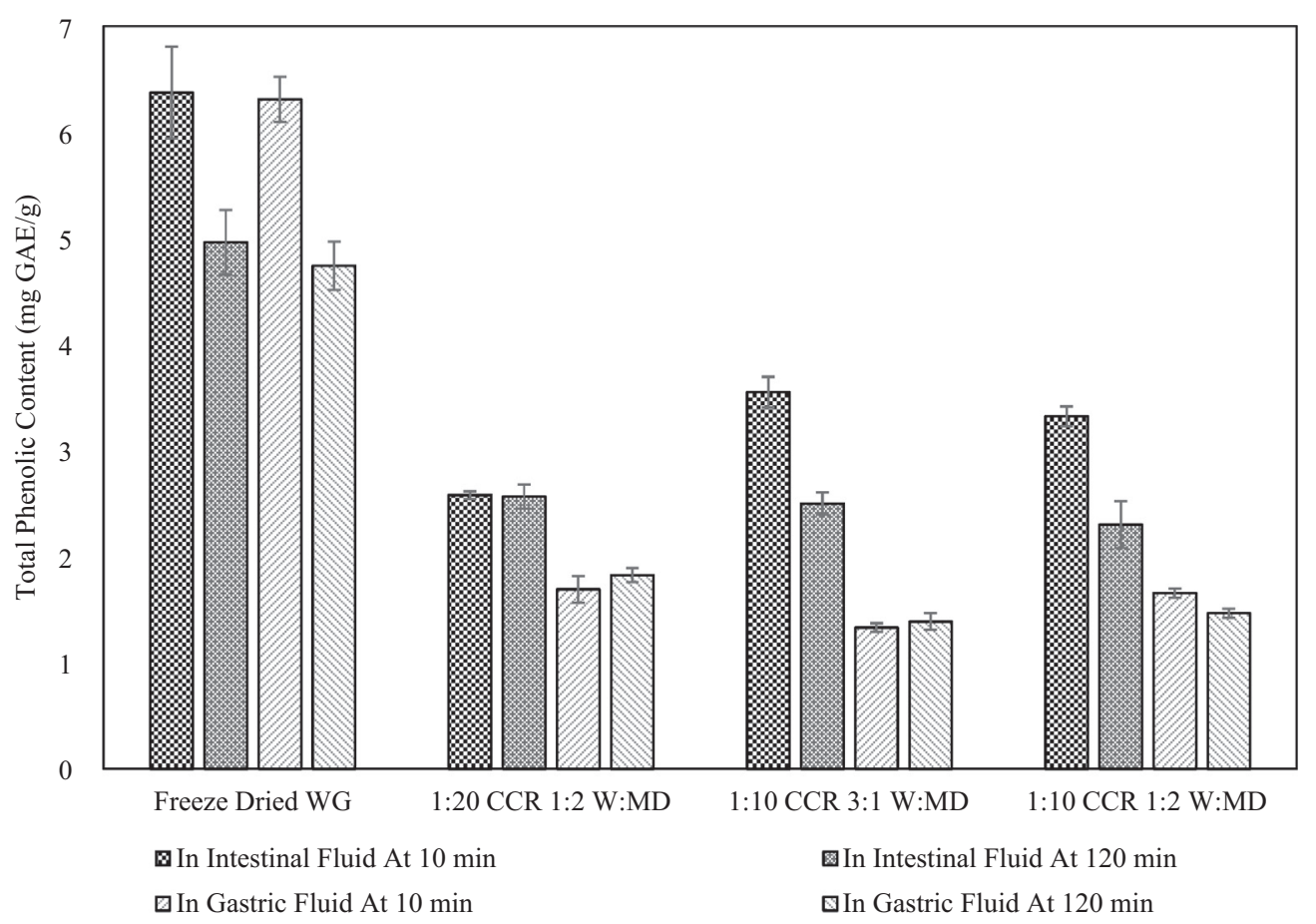

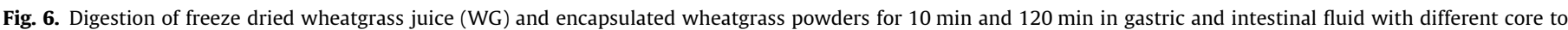
coating ratios (CCR), whey protein isolate (W) and maltodextrin (MD) contents. Means are represented as mg GAE (gallic acid equivalent)/g powder.

Table 2

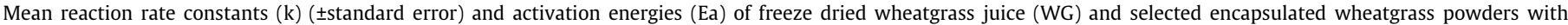
different core to coating ratios (CCR), whey protein isolate (W) and maltodextrin (MD) contents for 1 hour with $40{ }^{\circ} \mathrm{C}, 55^{\circ} \mathrm{C}$ and $70{ }^{\circ} \mathrm{C}$

\begin{tabular}{|c|c|c|c|c|}
\hline & WG & 1:10 CCR 3:1 W:MD & 1:20 CCR 1:2 W:MD & 1:10 CCR 1:2 W:MD \\
\hline $\mathrm{k}_{40}{ }^{\circ} \mathrm{C}\left(\mathrm{min}^{-1}\right)$ & $0.04312 \pm 0.0051$ & $0.1351 \pm 0.0007$ & $0.05343 \pm 0.0226$ & $0.04515 \pm 0.0019$ \\
\hline $\mathrm{R}^{2}$ & 0.8511 & 0.9949 & 0.9833 & 0.997 \\
\hline $\mathrm{k}_{55^{\circ} \mathrm{C}}\left(\min ^{-1}\right)$ & $0.06231 \pm 0.0231$ & $0.2180 \pm 0.0451$ & $0.09364 \pm 0.0025$ & $0.1245 \pm 0.0395$ \\
\hline $\mathrm{R}^{2}$ & 0.9409 & 0.9784 & 0.9917 & 0.974 \\
\hline $\mathrm{k}_{70{ }^{\circ} \mathrm{C}}\left(\mathrm{min}^{-1}\right)$ & $0.04506 \pm 0.0151$ & $0.1993 \pm 0.0283$ & $0.08922 \pm 0.0068$ & $0.1555 \pm 0.0068$ \\
\hline $\mathrm{R}^{2}$ & 0.9656 & 0.9797 & 0.9634 & 0.9883 \\
\hline $\mathrm{Ea}(\mathrm{kJ} / \mathrm{mol})$ & 1.6222 & 11.8141 & 15.5139 & 37.1221 \\
\hline
\end{tabular}

$\mathrm{W}: \mathrm{MD}$ ratio of 3:1. As expected for each temperature the lowest activation energy was calculated for the WGP without encapsulation. A sample of the CCR ratio 1:10 and $W$ :MD ratio of $1: 2$ had higher activation energy suggesting that this formulation provided better stability of WGJ against thermal treatment. Model fitting and experimental data recorded at different temperatures are also given in the Supplementary file.

\section{Conclusion}

Wheatgrass juice was successfully encapsulated with freeze dryer by using whey protein isolate and maltodextrin as coating materials. Encapsulated powders were analyzed for total phenolic contents, antioxidant activity, particle size, moisture and surface morphology. Also, in vitro studies in gastric and intestinal juices and thermal stability were studied. Results obtained confirmed that encapsulation could protect the high phenolic content and antioxidant activity. WGPs showed good stability against gastric juices and thermal treatment whereas they released most of their constituents in the intestinal juice. The best formulation for the capsules was determined as CCR ratio of 1:10 and W:MD proportion of 1:2 which provided higher antioxidant activity, higher phenolic content with high encapsulation efficiency and also good stability in gastric juices as well as high temperatures. Total pheno- lic content changes at different temperatures were investigated using the fractional conversion kinetic model. Reaction rate constants and activation energies of selected WGPs were calculated. Overall, it was suggested that wheatgrass powder could be used as a functional food ingredient due to its high antioxidant activity, phenolic content and thermal and gastric digestive resistance properties for different food applications.

\section{Acknowledgement}

This study was supported by Ministry of Science, Industry and Technology of Republic of Turkey [Grant number 0364-TGSD2015].

\section{Appendix A. Supplementary data}

Supplementary data associated with this article can be found, in the online version, at http://dx.doi.org/10.1016/j.jff.2016.11.010.

\section{References}

Adom, K. K., \& Liu, R. H. (2002). Antioxidant activity of grains. Journal of Agricultura and Food Chemistry, 50(21), 6182-6187. http://dx.doi.org/10.1021/jf0205099.

Akcan Kardas, T., \& Durucasu, I. (2014). A new analytical method for the determination of phenolic compounds and their antioxidant activities in 
different wheat grass varieties. Ekoloji, 23(90), 73-80. http://dx.doi.org/ 10.5053/ekoloji.2014.909.

Anal, A. K., \& Singh, H. (2007). Recent advances in microencapsulation of probiotics for industrial applications and targeted delivery. Trends in Food Science and Technology, 18(5), 240-251. http://dx.doi.org/10.1016/j.tifs.2007.01.004.

Augustin, M. A., Sanguansri, L., \& Lockett, T. (2013). Nano- and micro-encapsulated systems for enhancing the delivery of resveratrol. Annals of the New York Academy of Sciences, 1290, 107-112. http://dx.doi.org/10.1111/nyas.12130.

Aydos, O., Avci, A., Ozkan, T., Karadag, A., \& Gurleyik, E. (2011). Antiproliferative, apoptotic and antioxidant activities of wheatgrass (Triticum aestivum L.) extract on CML (K562) cell line. Turkish Journal of. Medical Science, 41(4), 657-663. http://dx.doi.org/10.3906/sag-0912-425.

Bae, E. K., \& Lee, S. J. (2008). Microencapsulation of avocado oil by spray drying using whey protein and maltodextrin. Journal of Microencapsulation, 25(8), 549-560. http://dx.doi.org/10.1080/02652040802075682.

Beckman, C. (2000). Phenolic-storing cells: keys to programmed cell death and periderm formation in wilt disease resistance and in general defence responses in plants. Physiological and Molecular Plant Pathology, 57, 101-110.

Benincasa, P., Galieni, A., Manetta, A. C., Pace, R., Guiducci, M., Pisante, M., et al (2015). Phenolic compounds in grains, sprouts and wheatgrass of hulled and non-hulled wheat species. Journal of the Science of Food and Agriculture, 95 1795-1803. http://dx.doi.org/10.1002/jsfa.6877.

Beta, T., Sapirstein, H. D., \& Mpofu, A. (2006). Genotype and environmental variation in phenolic content, phenolic acid composition, and antioxidant activity of hard spring wheat. Journal of Agricultural and Food Chemistry, 54, 1265-1270.

Chen, L., Remondetto, G. E., \& Subirade, M. (2006). Food protein-based materials as nutraceutical delivery systems. Trends in Food Science and Technology, 17(5) 272-283. http://dx.doi.org/10.1016/j.tifs.2005.12.011.

Drusch, S., Serfert, Y., Van Den Heuvel, A., \& Schwarz, K. (2006). Physicochemical characterization and oxidative stability of fish oil encapsulated in an amorphous matrix containing trehalose. Food Research International, 39(7), 807-815. http://dx.doi.org/10.1016/j.foodres.2006.03.003.

Durairaj, V., Shakya, G., Pajaniradje, S., \& Rajagopalan, R. (2014). Effect of wheatgrass on membrane fatty acid composition during hepatotoxicity induced by alcohol and heated PUFA. The Journal of Membrane Biology, 247(6) 515-521. http://dx.doi.org/10.1007/s00232-014-9661-0.

Dziezak, J. (1988). Microencapsulation and Encapsulated Ingredients. Food Technology, 42(4), 136-151.

Finney, J., Buffo, R., \& Reineccius, G. A. (2002). Effects of type of atomization and processing temperatures on the physical properties and stability of spray-dried flavors. Journal of Food Science, 67(3), 1108-1114. http://dx.doi.org/10.1111/ j.1365-2621.2002.tb09461.x.

Fu, T. J., Abbott, U. R., \& Hatzos, C. (2002). Digestibility of food allergens and nonallergenic proteins in simulated gastric fluid and simulated intestinal fluid A comparative study. Journal of Agricultural and Food Chemistry, 50(24), 7154-7160. http://dx.doi.org/10.1021/jf020599h.

Gharsallaoui, A., Roudaut, G., Chambin, O., Voilley, A., \& Saurel, R. (2007) Applications of spray-drying in microencapsulation of food ingredients: an overview. Food Research International, 40(9), 1107-1121. http://dx.doi.org 10.1016/j.foodres.2007.07.004.

Goula, A. M., \& Adamopoulos, K. G. (2012). A method for pomegranate seed application in food industries: seed oil encapsulation. Food and Bioproducts Processing, 90(4), 639-652. http://dx.doi.org/10.1016/j.fbp.2012.06.001.

Hanninen, O., Rauma, A., Kaartinen, K. \& Nenonen, M. (1999). Vegan diet in physiological health promotion. Acta Physiologica Hungarica, 86(3-4), 171-180.

Ingold, K. (1968). Inhibitition of autoxidation. In Oxidation of Organic Compounds (pp. 296-305). American Chemical Society.

Jafari, S. M., Assadpoor, E., He, Y., \& Bhandari, B. (2008). Re-coalescence of emulsion droplets during high-energy emulsification. Food Hydrocolloids, 22(7), 1191-1202. http://dx.doi.org/10.1016/j.foodhyd.2007.09.006.

Knockaert, G., Pulissery, S. K., Lemmens, L., Van Buggenhout, S., Hendrickx, M., \& Van Loey, A. (2012). Carrot ??-carotene degradation and isomerization kinetics during thermal processing in the presence of oil. Journal of Agricultural and Food Chemistry, 60(41), 10312-10319. http://dx.doi.org/10.1021/jf3025776.

Kong, F., \& Singh, R. P. (2009). Modes of disintegration of solid foods in simulated gastric environment. Food Biophysics, 4(3), 180-190. http://dx.doi.org/10.1007/ s11483-009-9116-9.

Krawitzky, M., Arias, E., Peiro, J. M., Negueruela, A. I., Val, J., \& Oria, R. (2014) Determination of color, antioxidant activity, and phenolic profile of different fruit tissue of spanish "verde doncella" apple cultivar. International Journal of Food Properties, 17(10), 2298-2311. http://dx.doi.org/10.1080/ 10942912.2013 .792829$.

Kulkarni, S. D., Acharya, R., Nair, A. G. C., Rajurkar, N. S., \& Reddy, A. V. R. (2006). Determination of elemental concentration profiles in tender wheatgrass (Triticum aestivum L.) using instrumental neutron activation analysis. Food Chemistry, 95(4), 699-707. http://dx.doi.org/10.1016/j.foodchem.2005.04.006.

Li, C., Wang, J., Shi, J., Huang, X., Peng, Q., \& Xueb, F. (2015). Encapsulation of tomato oleoresin using soy protein isolate-gum aracia conjugates as emulsifier and coating materials. Food Hydrocolloids, 45, 301-308. http://dx.doi.org/10.1016 j.foodhyd.2014.11.022.
Maali, A., \& Mosavian, M. T. H. (2013). Preparation and application of nanoemulsions in the last decade (2000-2010). Journal of Dispersion Science and Technology, 34(1), 92-105. http://dx.doi.org/10.1080/ 01932691.2011.648498

Millqvist-fureby, A., \& Malmsten, M. (1999). Surface characterisation of freeze-dried protein/carbohydrate mixtures. Solutions, 191, 103-114.

Murali, S., Kar, A., Mohapatra, D., \& Kalia, P. (2014). Encapsulation of black carrot juice using spray and freeze drying. Food Science and Technology International, 21 (8), 604-612. http://dx.doi.org/10.1177/1082013214557843.

Nedovic, V., Kalusevic, A., Manojlovic, V., Levic, S., \& Bugarski, B. (2011). An overview of encapsulation technologies for food applications. Procedia Food Science, 1, 1806-1815. http://dx.doi.org/10.1016/j.profoo.2011.09.265.

Rajam, R., Karthik, P., Parthasarathi, S., Joseph, G. S., \& Anandharamakrishnan, C. (2012). Effect of whey protein - alginate wall systems on survival of microencapsulated Lactobacillus plantarum in simulated gastrointestinal conditions. Journal of Functional Foods, 4(4), 891-898. http://dx.doi.org/ 10.1016/j.jff.2012.06.006.

Ray, S., Raychaudhuri, U., \& Chakraborty, R. (2015). An overview of encapsulation of active compounds used in food products by drying technology. Food Bioscience, 13, 76-83. http://dx.doi.org/10.1016/j.fbio.2015.12.009.

Reineccius, G. A. (2004). The spray drying of food flavors. Drying Technology, 22(6), 1289-1324. http://dx.doi.org/10.1081/DRT-120038731.

Robert, P., Gorena, T., Romero, N., Sepulveda, E., Chavez, J., \& Saenz, C. (2010) Encapsulation of polyphenols and anthocyanins from pomegranate (Punica granatum) by spray drying. International Journal of Food Science and Technology, 45(7), 1386-1394. http://dx.doi.org/10.1111/j.1365-2621.2010.02270.x.

Sanchez-Rabaneda, F., Jauregui, O., Lamuela-Raventos, R. M., Bastida, J., Viladomat, F., \& Codina, C. (2003). Identification of phenolic compounds in artichoke waste by high-performance liquid chromatography-tandem mass spectrometry. Journal of Chromatography A, 1008(1), 57-72. http://dx.doi.org/10.1016/S00219673(03)00964-6.

Sansone, F., Picerno, P., Mencherini, T., Villecco, F., D’Ursi, A. M., Aquino, R. P., \& Lauro, M. R. (2011). Flavonoid microparticles by spray-drying: Influence of enhancers of the dissolution rate on properties and stability. Journal of Food Engineering, 103(2), 188-196. http://dx.doi.org/10.1016/j.jfoodeng.2010.10.015.

Sarkar, A., Horne, D. S., \& Singh, H. (2010). Pancreatin-induced coalescence of oil-inwater emulsions in an in vitro duodenal model. International Dairy Journal, 20 (9), 589-597. http://dx.doi.org/10.1016/j.idairyj.2009.12.007.

Schmidt, D., Meijer, R., Slangen, C., \& Van Beresteijn, E. (2006). Raising the pH of the pepsin-catalysed hydrolysis of bovine whey proteins increases the antigenicity of the hydrolysates. Clinical \& Experimental Allergy, 25(10), 1007-1017.

Shahidi, F., \& Han, X. (1993). Encapsulation of food ingredients. Critical Reviews in Food Science and Nutrition, 33(6), 501-547.

Shukla, V., Vashistha, M., \& Singh, S. N. (2009). Evaluation of antioxidant profile and activity of amalaki (Emblica officinalis), spirulina and wheat grass. Indian Journal of Clinical Biochemistry, 24(1), 70-75. http://dx.doi.org/10.1007/s12291009-0012-3.

Soottitantawat, A., Bigeard, F., Yoshii, H., Furuta, T., Ohkawara, M., \& Linko, P. (2005). Influence of emulsion and powder size on the stability of encapsulated Dlimonene by spray drying. Innovative Food Science and Emerging Technologies, 6 (1), 107-114. http://dx.doi.org/10.1016/j.ifset.2004.09.003.

Sun, T. Y., Li, J. S., \& Chen, C. (2014). Effects of blending wheatgrass juice on enhancing phenolic compounds and antioxidant activities of traditional kombucha beverage. Journal of Food and Drug Analysis, 23(4), 709-718. http:// dx.doi.org/10.1016/j.jfda.2015.01.009.

Takahashi, T., Okiura, A., Saito, K., \& Kohno, M. (2014). Identification of phenylpropanoids in fig (Ficus carica L.) leaves. Journal of Agricultural and Food Chemistry, 62(41), 10076-10083. http://dx.doi.org/10.1021/jf5025938.

Vandenberg, G. W., Drolet, C., Scott, S. L., \& De la Noüe, J. (2001). Factors affecting protein release from alginate-chitosan coacervate microcapsules during production and gastric/intestinal simulation. Journal of Controlled Release, 77 (3), 297-307. http://dx.doi.org/10.1016/S0168-3659(01)00517-X.

Wang, B. S., Li, B. S., Zeng, Q. X., \& Liu, H. X. (2008). Antioxidant and free radical scavenging activities of pigments extracted from molasses alcohol wastewater. Food Chemistry, 107(3), 1198-1204. http://dx.doi.org/10.1016/ j.foodchem.2007.09.049.

Wang, W., \& Zhong, Q. (2014). Properties of whey protein-maltodextrin conjugates as impacted by powder acidity during the Maillard reaction. Food Hydrocolloids, 38, 85-94. http://dx.doi.org/10.1016/j.foodhyd.2013.11.018.

Young, S., Sarda, M., \& Rosenberg, M. (1993). Microencapsulating properties of whey proteins. 1. microencapsulation of anhydrous milk fat. Journal of Dairy Science, 76(10), 2868-2877.

Zendehbad, S. H., Mehran, M. J., \& Malla, S. (2014). Flavonoids and phenolic content in wheat grass plant (Triticum aestivum). Asian Journal of Pharmaceutical and Clinical Research, 7(4), 184-187.

Zheng, L., Ding, Z., Zhang, M., \& Sun, J. (2011). Microencapsulation of bayberry polyphenols by ethyl cellulose: Preparation and characterization. Journal of Food Engineering, 104(1), 89-95. http://dx.doi.org/10.1016/j.jfoodeng.2010.11.031. 